\title{
A Comparison between the Images of Cui Yingying and Juliet
}

\author{
Ruolan Tang ${ }^{*}$, Guangrong Liao ${ }^{2}$ \\ ${ }^{1}$ English Major, Foreign Studies College of Hunan Normal University, Changsha, China \\ ${ }^{2}$ Foreign Studies College of Hunan Normal University, Changsha, China \\ Email: *136178025@qq.com
}

How to cite this paper: Tang, R.L. and Liao, G.R. (2019) A Comparison between the Images of Cui Yingying and Juliet. Open Access Library Journal, 6: e5373. https://doi.org/10.4236/oalib.1105373

Received: April 3, 2019

Accepted: May 27, 2019

Published: May 30, 2019

Copyright (c) 2019 by author(s) and Open Access Library Inc.

This work is licensed under the Creative Commons Attribution International License (CC BY 4.0).

http://creativecommons.org/licenses/by/4.0/

\begin{abstract}
Romeo and Juliet and The Romance of the Western Chamber are both great monuments that eulogize love and break through the feudalistic constraints in human history. The previous research usually focuses on the artistic aesthetics and thought and culture of the drama, and little has discussed about the differences and similarities of Cui Yingying and Juliet and its causes. Both Cui Yingying and Juliet are pioneers, who have outstanding appearance and revolt against feudalism of an era, but after careful reading, we can see that the former one is passionate and keyed-up while the later one is periphrastic and cautious. Appreciating two characters together to figure out the reasons behind the differences helps us to comprehend the similarities and differences between Chinese and foreign literature better, at the same time to perceive the marks of western and Chinese culture that engrave on the soul of the two characters.
\end{abstract}

\section{Subject Areas}

Literature

\section{Keywords}

Cui Yingying, Juliet, Differences and Similarities

\section{Introduction}

The classic drama of British drama master Shakespeare-Romeo and Juliet and China's masterpiece-The Romance of the Western Chamber are both excellent works which are high-sounding songs that extol the struggle to free from feudal shackles and the realization of the freedom of marriage and love. These two plays are not authors' originally created works, but adaptations of others' works. 
The dramas express the theme of rebellion against feudalism by portraying the twists and turns of young men and women who pursue love. As an enlightenment work of human liberation, the two plays have survived for hundreds of years, and even remain fresh throughout the history. They have surpassed the shackles of time and space and respectively become the classics of Chinese and Western drama culture. The stories take place in a feudal era where women are demanding. The courage and boldness of the heroines Cui Yingying and Juliet in pursuit of love are amazing and worth highly praise; however, the distinct differences between the two characters portrayed in the dramas are the outstanding differences in personality traits. Although from the literary origin, it seems that Juliet and Cui Yingying's images are not related at all, but we can discover the similarities and heterogeneities between the two. Through a comparative analysis of Juliet and Cui Yingying, we will find similar themes appeal in the two works and different features of western and eastern culture through the differences of characters.

\section{Similarities of Characters}

The female protagonists described in Romeo and Juliet and The Romance of the Western Chamber are all aristocratic girls with a beautiful appearance and a delicate figure. The fourteen-year-old Juliet meets Romeo in a ball, and the nineteen-year-old Yingying encounters Zhang Sheng in the Buddha Hall. Since then, the chaotic emotional world has ushered in the beginning of love, and it is not self-control. They rebelled against their own families, growing up from a soft girl to a strong warrior. In the end, Juliet and Romeo declared that they would never compromise to the family by death, and Yingying and Zhang Sheng ensured perpetual alliance between the two families after experiencing much suffering.

\subsection{Beautiful, Charming, and Innocent Aristocratic Girls}

The genesis of the emotion's appearance in Romeo and Juliet and The Romance of the Western Chamber are the same, that is, "love at first sight." Loving at first sight means that all starts from "seeing". The unfamiliar Juliet and Romeo and Cui Yingying and Zhang Sheng did not know each other originally, but the girls touched the man's heart at the first meeting because of the physical characteristics of Juliet and Cui Yingying-beautiful and charming.

Romeo first saw the strange lady at the dance ball and could not help but sigh:

"O, she doth teach the torches to burn bright!

It seems she hangs upon the cheek of night

Like a rich jewel in an Ethiope's ear;

Beauty too rich for use, for earth too dear!

So shows a snowy dove trooping with crows,

As yonder lady o'er her fellows shows.

The measure done, I'll watch her place of stand,

And, touching hers, make blessed my rude hand. 
Did my heart love till now? forswear it, sight!

For I ne'er saw true beauty till this night." [1]

Shakespeare uses a series of dazzling words to form the visual impact of the language, In the original work, "Romeo's praise of body-related words are 'check', 'ear', 'hand', and the words that describe the metaphor of skin are 'bright', 'snowy dove'", etc. [2] These words describe the attraction of strange Juliet to Romeo from the perspective of him. Juliet is pretty and graceful, and her beauty is far beyond other girls. Romeo forgets where he is. Since he could not suppress the praises, it's not hard to imagine how beautiful Juliet is.

Cui Yingying is also fascinated by Zhang Sheng in their first meeting. In the fold of "Jingyan", Zhang runs into Cui when visiting the Buddha Temple, and he sighs with emotion again and again, "SiZhe Ban Ke Xi Niang De Pang Er Han CengJian", "Shui Xiang Zhe Si Li Yu Shen Xian” "Jie Wu Yao ZhiJioa You Ruan, Qian Ban Niao Na, Wan Ban Yi Ni, Si Chui Liu Wan Feng Qian” [3]. In the fold of "Lianyin", Zhang Sheng meets Cui Yingying, who is the lady of Xiangguo (prime minister), for the second time, and the cute woman in his eyes has another kind of charm: "Si Xiang Ling FeiZi, Xie Yi Shun Miao Zhu Fei; Ru Yu Chang E, Wei Xian Chan Gong Su Ying” [4]. Here the work compares Cui Yingying as fairies like XiangFei and Chang E. It portrays the fantastic posture of Yingying under the moonlight by vivid expression and bold outline. The fold of "Naozhai" carefully delineates Yingying, "Ying Tao Zui", "Fen Bi Li HuaMian", and "Yang Liu Yao" from the eyes of Zhang Sheng. The image of Cui Yingying is so vivid as if she is standing on the paper. The author also uses the indirect description. He describes the beauty of the Yingying by using the reflections of the temple monks, who are eager to see Yingying.

The beginning of love in the two dramas, if the heroines are not beautiful, will not exist at all. The two dramatists unanimously arranged "fall in love in the first sight" to show the fair appearance as a characteristic of the heroines, highlighting the purity of their love and creating a pure and beautiful image of them.

\subsection{Courageous and Rebellious Love Warriors}

Faced with the contradiction between love and feudal forces, Juliet and Cui Yingying both show extraordinary courage and wisdom and persistent pursuit of love, and finally break through the barriers of feudal ethics.

Cui Yingying is the daughter of Xiangguo (prime minister) of the dynasty, born in a famous family, and grows up in the deep boudoir. The old lady (her mother) is strict with the discipline to her, and even if she walks out on the weekdays, she will be severely reprimanded by her mother. The old lady has also placed a matchmaker to supervise her words and deeds. This kind of "living in the deep of the house" is a feudal ethics, and Cui Yingying has a desire for freedom.

In order to highlight Cui Yingying's rebellious character, WangShifu (the author) arranged the time and place of the story in an ingenious way. The Rom- 
ance of the Western Chamber lets Cui Yingying and Zhang Sheng's love story happens in the environment of the temple. The temple is originally a pure, self-cultivation and self-cultivation land of Buddhism; however, Cui Yingying falls in love in the place and hangs around with Zhang Sheng in the western chamber. The land of Buddhism has become a warm bed for the birth of love. Not only that, at that time Cui Xiangguo's (Cui Yingying's father's) coffin is still parked in the Pujiu Temple. According to the feudal ethics: "Fu Sang Wei Man, Wei De Cheng He." [3] Miss Xiangguo (Cui Yingying), who is still in the mourning period, cast amorous glances at Zhang in the solemn ceremony to release souls from purgatory. What's more, later, she celebrates her love extremely in the western chamber, and leaves a romantic affair during the mourning. The "extraordinary" move of Cui Yingying is the ingenious testimony of her rebellious character.

Juliet grows up in the Capulet family in the city. She, the apple of the family's eyes, is gentle and lively. The parents give Juliet a certain choice to choose her spouse, and hold a dance ball for her to find true husband; however, Juliet is fond of the clansman of the hostile family since centuries ago. Juliet's love is not only based on the handsome appearance, if not, why she is not interested in the romantic Paris. Juliet loves Romeo because of the similar ideas between them. They are dissatisfied with the sanctimonious churches. They oppose the precepts that violate human desires since the Middle Ages. They pursue true and free love. In that era, talking about "love" is a sinful matter. Juliet boldly commits this "sweet sin." She has private meeting with Romeo in the balcony which is a rebellion against the asceticism and hypocrisy of that era [5].

Juliet's actions are also the best proof of her rebellious spirit. After deciding her favorite person, Juliet deliberately inquiries about his identity. She throws her words "If he be married. My grave is like to be my wedding bed" [1].

Her words are so thoroughly determined from the beginning. When she learns that Romeo is the son of the opponent family, she tosses and turns on the bed because she can't sleep. She talks about her thoughts to the moon, and there is no hesitation in her words. She only says the steadfast and fiery love in her heart. Juliet does not look like Ophelia who let her father to decide her marriage, but seeks the help from the godfather to marry Romeo secretly, and to fight with family's power with utmost wisdom. In order to escape from the family's surveillance, she does not hesitate to drink the sleeping pills, and the ending is even more woeful, she follows the pace of Romeo with a smile on her mouth. Juliet's actions are not only a rebellion against arranged marriages, but also a rebellion against the concept of family feuds. A docile obedient girl, on the road of chasing love, grows up to be a warrior who is brave, faithful and faces death unflinchingly.

The charm of Juliet's and Cui Yingying's lies in their courage and determination to fight against the feudalism. They are the beautiful light of that era, representing the yearning and pursuit of people which spans time and space and 
becomes the spiritual wealth of mankind forever.

\section{Differences between the Characters}

When facing love, the two beautiful and passionate aristocratic girls show their unique sides. The concept of love and marriage is not only the embodiment of people's ideas but also of a deep culture of a nation. Different cultural backgrounds inevitably affect and limit the way of love and marriage perception which lead to the two heroines revealing different characters [6] [7] [8].

\subsection{Cui Yingying: A Profound and Restrained Traditional Classical Woman}

Cui Yingying's image is complex and profound. Her struggle is profound, introverted yet consolidate step by step. Her heart is hot yet not rushing, deep yet not explicit. Even if her inner world is turbulent, she can still be quiet on the surface. The characteristics of traditional Chinese classical women are undoubtedly demonstrated.

Cui Yingying's expression of love is euphemistic and implicit, and the feature runs through the beginning and end of the drama. The description of her first meeting with Zhang Sheng is worthy of the readers' taste: Yingying did not want to take a direct look at Zhang Sheng, just smiling by flowers, and she glances at Zhang Sheng full of emotion. "Lin QuQiu Bo Na Yi Zhuan". The meaning of looking is revealed explicitly.

Cui Yingying and Zhang Sheng's tease also shows Cui Yingying's intelligence. The first time she conveys her tender feeling to Zhang Sheng is to write a poem across the wall, but she is still in the stage of determining each other's minds. As she has already determined her mind, she takes action immediately. When being trapped by thieves, Sun Feihu threatened that if Cui Yingying is not sent out within three days he will burn the temple. The monks who are besieged together are helpless. Cui Yingying does not panic. She offers to the old lady a stratagem. After obtaining the consent, she announces to the people in the temple with the help of the presbyter: "Dan You Tui Bing ZhiCe, Dao Pei Fang Lian, Duan Song Yingying Yu Zhi Wei Qi" [3] All the men in the temple are monks who gain an insight of the worldly affairs but Zhang Sheng is an exception. It is obvious how unfair the spouse-seeking notice is. Zhang Sheng really does not let the hope down, and finds his own friend, General White Horse, to drive away the thieves. Cui Yingying's strategy can be described as kill two birds with one stone: fulfilling the intention of her loved one to save the beauty, and raising his prestige in front of his mother. Yingying cleverly achieves the natural arrangement with Zhang Sheng through her mother's promise, and relieves the engagement with ZhengHeng [9]. Cui Yingying's intelligence can be seen from her thoughts of innumerable twists. We can easily see that she is cautious and careful, and a young girl with a little bit of savvy.

The love between Cui Yingying and Zhang Sheng endes in a happy reunion. 
Although they overcomes countless disasters during the process, the drama eventually returns to regular and becomes a story of the number one scholar marries the daughter of Xiangguo [10]. After a heated struggle, Cui Yingying finally returns to the real life of feudalism. After all, she is not a new woman who has experienced the baptism of humanism thoughts, but a feminine under the feudal vulgar education. The seemingly happy ending of The Romance of the Western Chamber implies infinite sorrow. The author uses this perfect ending to make "emotion" win a harmonious victory in a situation that seems to be "reasonable" and conceal the bitterness of compromising the feudal forces.

\subsection{Juliet: An Innocent Decisive New Woman of Humanism}

Shakespeare's Juliet has no idea about what are profound and introverted. She is innocent and courageous. She has passion for deep love and courage to break the mundane principles. She is the beautiful ideal of Shakespeare and an embodiment of a new era of humanism.

Juliet is agitated and brave. After being awakened by love, she presses forward with indomitable will. Juliet's personality traits can be analyzed from two small climaxes in the drama. The first small climax is "meeting secretly in the garden, vowing a solemn pledge of love", she secretly marries Romeo the next day, and prepares to flee from Verona and elope to other places. Juliet is willing to change her family name for love, showing her courage and free and easy, which reflects the characteristics of the new women in the Renaissance.

The second little climax is that "Tybalt was stabbed to death, Juliet was forced to marry." On the day of the marriage, Romeo stabbes Tybalt. Prince Escalus orders Romeo to be exceled. Juliet expresses her determination to the priest directly:

"Tell me not, friar, that thou hear'st of this,

Unless thou tell me how I may prevent it:

If, in thy wisdom, thou canst give no help,

Do thou but call my resolution wise,

And with this knife I'll help it presently.

God join'd my heart and Romeo's, thou our hands;

And ere this hand, by thee to Romeo seal'd,

Shall be the label to another deed,

Or my true heart with treacherous revolt

Turn to another, this shall slay them both:

Therefore, out of thy long-experienced time,

Give me some present counsel, or, behold,

'Twixt my extremes and me this bloody knife

Shall play the umpire, arbitrating that

Which the commission of thy years and art

Could to no issue of true honourbring.

Be not so long to speak; I long to die, 
If what thou speak'st speak not of remedy" [1].

Juliet in love looks like a moth that is approaching the burning fire, even if the flame of love will burn her to ashes, and she does not hesitate. Her expression of love is fierce. She dares to say and to do it without being affectedly bashful. She puts all her minds into action. If she can only express love by death, then Juliet will be willing to die.

Destiny seems to be joking with Juliet. She originally wants to take the medicine to pretend dying, so that she could run away with her loved one; however, the priest's step is too late that Romeo commits suicide. Juliet, who wakes up from her sleep, looks at the body of the lover lying next to her. She only feels that life is no longer cherishing, so she cuts her throat to achieve the completeness of love in another world. Juliet is passionate about love, and her tragedy has aroused the pity of millions of readers. The deep sympathy has stirred up people's reflection to the existing order of society. Just as Hegel analyzes the image of Juliet and arbitrates: "Only at the most difficult test moment did she appear as if a rose suddenly put its stamens and every wrinkle appeared, and as if a fresh spring lurking in the depths of the soul burst out unexpectedly, so that we could see all the strong strength of the soul" [11] [12] [13]. Faced with the ruthlessly teasing of the irresistible fate, Juliet holds a memorial ceremony for her love with blood, and the radical action reflects her unrestrained emotion, naivety with boldness of vison.

Juliet is a simple and passionate poem, a water of a clear mirror. The inside is the same as the outside. Her body exudes the ideal beauty of romanticism. For love, her delicate body can grow hard armor, and she wears it in the war with the family. Juliet is a typical agile and courage humanistic new female image.

\section{Summary}

In summary, Juliet and Cui Yingying are the two typical artistic images in the history of Western and Chinese drama, and they have a vital influence on the status and artistic value of literature. Shakespeare and Wang Shifu are influenced by their respectively regional cultures. The influence of national culture and the times on the authors is directly reflected in the protagonists' unique characters. The implicit restraint in Chinese culture and the enthusiasm in Western culture are the reasons why Cui Yingying's performance is restraint and Juliet's performance is exposed. Although due to the limitations of the times, the images of the two heroines are different, they are brilliant, witty and determined in the pursuit of love-independent battlefield, so that they are respected by the future generations of readers. In a specific historical environment, Cui Yingying's and Juliet's rebellion against the feudal forces and family have a distinct meaning. As a new force, they boldly took the first step and issued a powerful roar to the feudal forces. It provides powerful spiritual motivation for the self-conscious enlightenment and self-liberation of the people in the feudal society which has eternal vitality and the unrepeatable artistic value and has laid the foundation for the 
development of later literature.

\section{Conflicts of Interest}

The authors declare no conflicts of interest regarding the publication of this paper.

\section{References}

[1] Shakespeare, W. (1988) Romeo and Juliet. Bantam Books, USA.

[2] Zhang, S.J. (2004) The Tragedy of Romeo and Juliet and the Key Factors of Movie Adaptation. Contemporary Cinema, No. 3, 107-109.

[3] Wang, S.P. (1994) The Romance of the Western Chamber. People's Literature Publishing House, Beijing.

[4] Yue, S.H. (2007) On the Beauty of Yingyingi: Reinterpretation of the Image of Cui Yingying in The Romance of the Western Chamber. Journal of Mudanjiang College of Education, No. 3, 16.

[5] Zhu, Y.X. and Yu, Q.Y. (2006) The Comprehension of The Tragedy of Romeo and Juliet. Journal of Qinghai Junior Teachers' College, No. 6, 130-132.

[6] Gu, C.J. (2015) The Love View Comparison between The Romance of the Western Chamber and The Tragedy of Romeo and Juliet. Anhui Literature, No. 8.

[7] Yang, L. (2008) Fall in Love in Dreams, Break Love in Dreams: Viewing the Love View of Tang and Shakespeare from Du Li Niang and Juliet. Appreciation of Famous Literary Work, No. 22, 82-85.

[8] Wang, R.P. (1999) The Western Woman's Melancholy Complex of Du Li Niang's: One of the Translations Reaction of the Peony Pavilion. Foreign Languages and Their Teaching, No. 10, 51-54.

[9] Jia, X.Q. (2008) On the Differences between the Characters of Cui Yingying and Du Liniang. Journal of Shangqiu Teachers College, No. 11, 30-33.

[10] Lang, J. (2001) The Romance of the Western Chamber and the Chinese Love View. Appreciation of Famous Literary Work, No. 2, 47-51.

[11] Zhou, L.Y. (1998) Similarities and Differences between the Tragedy Images of Juliet and Du Liniang. Journal of Qinghai Junior Teachers' College, No. 6, 56.

[12] Li, Z.H. (2009) The Path of Beauty. Tianjing Social Science Press, Tianjing.

[13] Lv, G.G. (2010) Viewing Shakespeare's View of Women from the Image of Juliet. Journal of Changzhi University, No. 6, 38-40. 